\title{
Antibacterial and Antibiofilm Effect of Low Viscosity Chitosan against Staphylococcus epidermidis
}

\author{
Inger Sofie Dragland, ${ }^{1}$ Håkon Valen Rukke, ${ }^{1}$ Ida S. R. Stenhagen, \\ Jessica Lönn-Stensrud, ${ }^{2}$ and Hilde M. Kopperud ${ }^{1}$ \\ ${ }^{1}$ Nordic Institute of Dental Materials (NIOM), Oslo, Norway \\ ${ }^{2}$ University of Oslo, Oslo, Norway \\ Correspondence should be addressed to Inger Sofie Dragland; ind@niom.no
}

Received 24 May 2016; Accepted 20 July 2016

Academic Editor: Joseph Falkinham

Copyright ( 2016 Inger Sofie Dragland et al. This is an open access article distributed under the Creative Commons Attribution License, which permits unrestricted use, distribution, and reproduction in any medium, provided the original work is properly cited.

\begin{abstract}
Aim. The aim of this study was to investigate the antibacterial and antibiofilm properties of low viscosity chitosan on S. epidermidis growth and biofilm formation. Methods and Results. The antibacterial and antibiofilm properties were investigated, during both planktonic growth and biofilm formation. This was performed using different concentrations in media and by coating on polystyrene surfaces. In addition, the bactericidal effect was investigated using a modified direct contact test. The results showed that low viscosity chitosan in media had both a bacteriostatic and bactericidal effect on planktonic growth and biofilm formation of S. epidermidis in a concentration dependent manner. Polystyrene discs coated with chitosan reduced both early biofilm formation $(6 \mathrm{~h})$ and late biofilm formation $(18 \mathrm{~h})$, as confirmed by scanning electron microscopy. The modified direct contact test showed a bactericidal effect. Conclusion. This study demonstrated that low viscosity chitosan has a bacteriostatic and bactericidal activity against $S$. epidermidis and that the activity is dependent on the amount of chitosan added. In addition, low viscosity chitosan reduced biofilm formation both when added to media and when coated on polystyrene surfaces. Significance and Impact of Study. Low viscosity chitosan could be a contribution to new treatment approaches of biofilm-related infections of S. epidermidis.
\end{abstract}

\section{Introduction}

Staphylococcus epidermidis, a Gram-positive, coagulasenegative staphylococcus (CNS) found naturally on the skin and mucous membranes of humans, is considered to be the major cause of infections on indwelling medical devices [1]. CNS, especially S. epidermidis, is the most common cause of healthcare-associated bloodstream infections [2]. Frequent use of medical implants has led S. epidermidis to develop into an opportunistic pathogen [3]. Biofilm formation is an important virulence factor associated with disease at implant surfaces. "The biofilm way of living" increases resistance against antibiotics and the immune system, making biofilmrelated infections difficult to treat [4]. Bacteria in biofilm show up to 1000 -fold lower susceptibility to various antimicrobial agents compared to bacteria growing in planktonic culture [5]. Treatment of patients with a chronic infection often involves removal of the infected tissue and replacement of the implant [6]. In addition, isolates of S. epidermidis from nosocomial environments are often resistant to multiple antibiotics $[7,8]$, which highlights the need for finding new modalities to treat and prevent biofilm-related infections.

Several natural compounds prevent biofilm formation with promising results while demonstrating low toxicity to human cells $[9,10]$. Chitosan is a natural polysaccharide, composed of glucosamine and $N$-acetyl glucosamine units linked by $\beta$-1,4-glycosidic bonds. The content of glucosamine is referred to as the degree of deacetylation (DD). Commercial chitosan is produced by partly deacetylating chitin, obtained from the exoskeleton of crustaceans. The molecular weight (MW) of chitosan may range from 50 to over $2000 \mathrm{kDa}$ and the DD from 50 to $95 \%$ [11]. Chitosan has chemical, biological, and antimicrobial properties enabling it for applications in a variety of purposes in food production, medicine, agriculture, cosmetics, and biotechnology [12]. Pharmaceutical applications have shown promising results, 
for instance, using chitosan as a part of artificial skin, in swabs for wound healing and in drug release [13]. Chitosan is suitable for coating and forms films with good strength and barrier properties and has been used in food preservation as a bacterial inhibitor [14, 15].

Chitosan exhibits antimicrobial activity against many different types of bacteria as well as fungi and yeasts [16]. The mechanism behind chitosan's antimicrobial property is linked to the positively charged amino groups. This property is dependent on the degree of deacetylation, which increases the total positive charge of chitosan and the affinity for the negatively charged surfaces of bacteria [17]. In addition, chitosan has shown promising antibiofilm properties, as chitosan-coated dental implants and poly(methyl methacrylate) surfaces can reduce biofilm formation $[18,19]$. Upon impregnation of cotton textile with chitosan, the material demonstrated antibacterial effects against isolated staphylococci from normal skin and was suggested as an alternative way to treat skin inflammation [20].

Chitosan is insoluble in most solvents but can be dissolved to a certain extent in dilute acids such as acetic acid, lactic acid, and hydrochloric acid [12]. The poor solubility of chitosan also limits its application. The molecular weight of chitosan has a great impact on the solubility and the viscosity of chitosan in solution. High molecular weight chitosans (HMWC) dissolve more poorly and give solutions of higher viscosity than low molecular chitosans (LMWC) $[21,22]$. To overcome this poor solubility, water-soluble chitosan is produced as an oligomer by enzymatic or chemical hydrolysis. Chitosan, LMWC and HMWC, and chitosan oligomers exhibit antibacterial activity against different types of bacteria, but several studies report chitosan to be more effective in inhibiting bacterial growth compared with chitosan oligomers [23, 24]. Also, differences in MW influence the antibacterial effect of chitosan, but this effect seems to depend on the type of bacteria tested and the effect is more influenced by concentration than by MW $[20,23]$.

The main goal of this study was to investigate the antimicrobial property of low viscosity chitosan (LVC) on S. epidermidis growth and biofilm formation, using chitosan dissolved in media and coated on polystyrene surfaces.

\section{Materials and Methods}

2.1. Staphylococcus epidermidis. A stock culture of S. epidermidis, ATCC 35984 , was prepared from a $-80^{\circ} \mathrm{C}$ culture in Brain Heart Infusion medium (BHI, Oxoid Ltd., Basingstoke, UK). The culture was incubated aerobically for 6 hours at $37^{\circ} \mathrm{C}$ before being distributed into tubes and frozen at $-20^{\circ} \mathrm{C}$. The day before the experiment, the stock culture was diluted $\left(1: 100\right.$ in BHI) and incubated overnight at $37^{\circ} \mathrm{C}$. For use in planktonic growth and biofilm experiments, the overnight culture was further diluted (1:100 in BHI). For use in the modified direct contact test (DCT), the overnight culture was centrifuged and resuspended in phosphate-buffered saline (PBS) (Lonza, Walkersville, USA) to approximately $1 \times$ $10^{8} \mathrm{CFU} \mathrm{mL} \mathrm{m}^{-1}$.

2.2. Test Solutions of LVC. Solutions of LVC from shrimp shells (Sigma-Aldrich 50494, St. Louis, USA, MW 150 kDa,

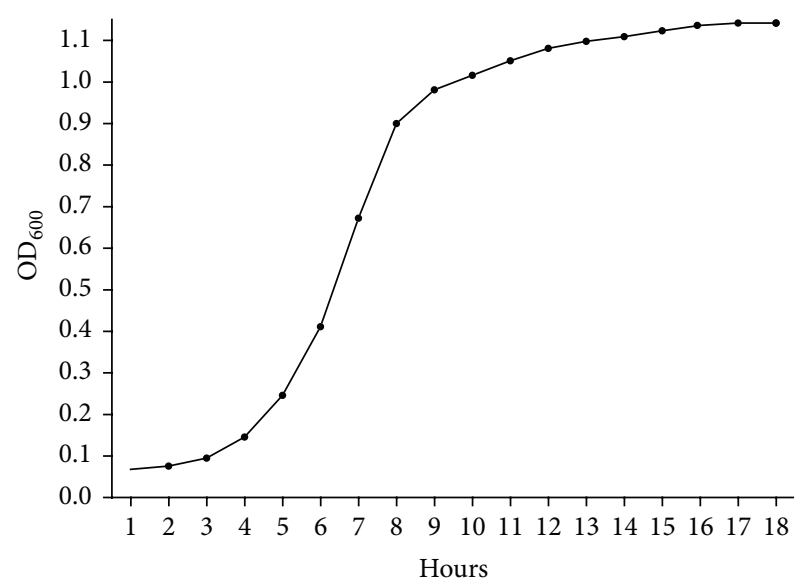

FIGURE 1: Planktonic growth of S. epidermidis in BHI, pH 5.9.

about $80 \%$ deacetylated) used for planktonic growth and biofilm formation experiments were made using BHI with $\mathrm{pH}$ 5.9. The $\mathrm{pH}$ was adjusted with acetic acid (VWR Prolabo, Fontenay-sous-Bois, France) from 7.2 to 5.9 to prevent precipitation of chitosan. To verify good growth at $\mathrm{pH} 5.9$, a growth curve of $S$. epidermidis over 18 hours was made by measuring optical density (OD) at $600 \mathrm{~nm}$ in a Multidetection Microplate Reader (Synergy H1, BioTek, USA) (Figure 1).

Solutions of LVC $(0-0.02 \% \mathrm{w} / \mathrm{v})$ in BHI for studies on planktonic growth and growth of biofilm were prepared using a stock solution of $1 \% \mathrm{w} / \mathrm{v} \mathrm{LVC}$ in $0.5 \%$ acetic acid.

Solutions of $\operatorname{LVC}(0.25,0.5$, and $1 \% \mathrm{w} / \mathrm{v})$ in BHI for coating of polystyrene discs and DCT experiments were prepared using 0.5\% hydrochloric acid (Merck, Darmstadt, Germany).

2.3. Planktonic Growth in Media with and without LVC. The effect of LVC on the planktonic growth of S. epidermidis was investigated using different concentrations of LVC in BHI. The control consisted of BHI medium with $\mathrm{pH}$ 5.9. The bacteria were incubated aerobically at $37^{\circ} \mathrm{C}$ for 18 hours. Bacteria suspensions were diluted in PBS and plated onto BHI agar using an automatic spiral plater (Whitley, Don Whitley Scientific Ltd., Shirly, UK) and incubated overnight at $37^{\circ} \mathrm{C}$. CFU were counted on the following day using a colony counter (Acolyte, Synbiosis, Cambridge, UK).

The experiments were performed with 4 parallels in 3 separate experiments. Live bacteria were expressed as CFU $\mathrm{mL}^{-1}$.

2.4. Growth of Biofilm in Media with and without LVC. Biofilm was established on polystyrene discs (d: $13 \mathrm{~mm}$; Thermanox $^{\circledR}$ Plastic Coverslips, Nunc ${ }^{\mathrm{TM}}$, Rochester, USA) in a 24-well microtiter plate (Sarstedt, Nümbrecht, Germany) in the presence of different concentrations of LVC in BHI. The discs were placed horizontally at the bottom of the wells and grown aerobically at $37^{\circ} \mathrm{C}$ for 18 hours on a tilt tray (30 tilts/min). At longer growth times, the biofilm tended to detach from the discs. The control consisted of BHI medium with $\mathrm{pH}$ 5.9. 
The discs with biofilm were washed in PBS to remove the unattached cells and placed in new wells before staining for 10 min with $0.1 \%$ safranin (Acros Organics, Glee, Belgium). After staining, the discs were placed in new wells and excess dye was removed by gently rinsing with PBS. The bound safranin was released from the biofilm with $30 \%$ acetic acid. Optical density (OD) at $530 \mathrm{~nm}$ was measured in a Multidetection Microplate Reader (Synergy H1, BioTek, USA).

The experiments were performed with 4 parallels in 3 separate experiments.

2.5. Modified Direct Contact Test (DCT). The test was performed in a 48-well microtiter plate. The microtiter plate was held in vertical position and the side wall of the wells was coated overnight at $37^{\circ} \mathrm{C}$ with $50 \mu \mathrm{L}$ of the LVC solutions. As control, $0.5 \% \mathrm{HCl}$ was used. The bacterial suspension $(10 \mu \mathrm{L}$, ca. $10^{6}$ bacteria) was placed onto the chitosan-coated wells. The plate was left at $37^{\circ} \mathrm{C}$ for 60 min to allow the bacteria to come into direct contact with the coating. PBS was added to the wells and diluted before $3 \times 50 \mu \mathrm{L}$ drops from each sample were plated on $\mathrm{BHI}$ agar and incubated overnight at $37^{\circ} \mathrm{C}$. CFU were counted on the following day.

A minimum of 8 parallels from two separate experiments were performed for each of the different concentrations and control. Live bacteria were expressed as CFU $\mathrm{mL}^{-1}$.

2.6. Growth of Biofilm on Polystyrene Discs Coated with LVC. Polystyrene discs were soaked for 2 hours in solutions of LVC and dried overnight under sterile conditions before biofilm was established. Discs soaked in $0,5 \% \mathrm{HCl}$ were used as control. In order to adjust the background (blanks), discs coated with LVC solutions corresponding to the test discs were run simultaneously with biofilm experiments.

The discs were washed with PBS before being placed in a 24 well microtiter plate and incubated for 6 and 18 hours on a tilt table (30 tilts/min) for the biofilm of $S$. epidermidis to be established. BHI with pH 5.9 was used in these experiments. After staining with $0,1 \%$ safranin and measurements of $\mathrm{OD}_{530}$, the results were adjusted with measured $\mathrm{OD}_{530}$ from blanks at respective concentrations of LVC.

The experiments were performed with 4 parallels in 3 separate experiments.

2.7. Scanning Electron Microscopy. Biofilms and LVC-coated discs were visualized using scanning electron microscopy (SEM). Biofilms and coatings were prepared as described above. After rinsing in PBS, the biofilms and coated discs with bacteria were fixed with $2.5 \%$ glutaraldehyde in $0.1 \mathrm{M}$ Sørensens buffer. Samples were dehydrated by rinsing the discs in ethanol, followed by sputter coating with gold palladium. Images were acquired using scanning electron microscopy (Philips XL 30 ESEM, Philips, Eindoven, Netherlands).

2.8. Statistical Analysis. The Student $t$-test for parametric independent data and the Mann-Whitney $U$ test for nonparametric independent data were used to find significant similarity or difference between the data for a significance

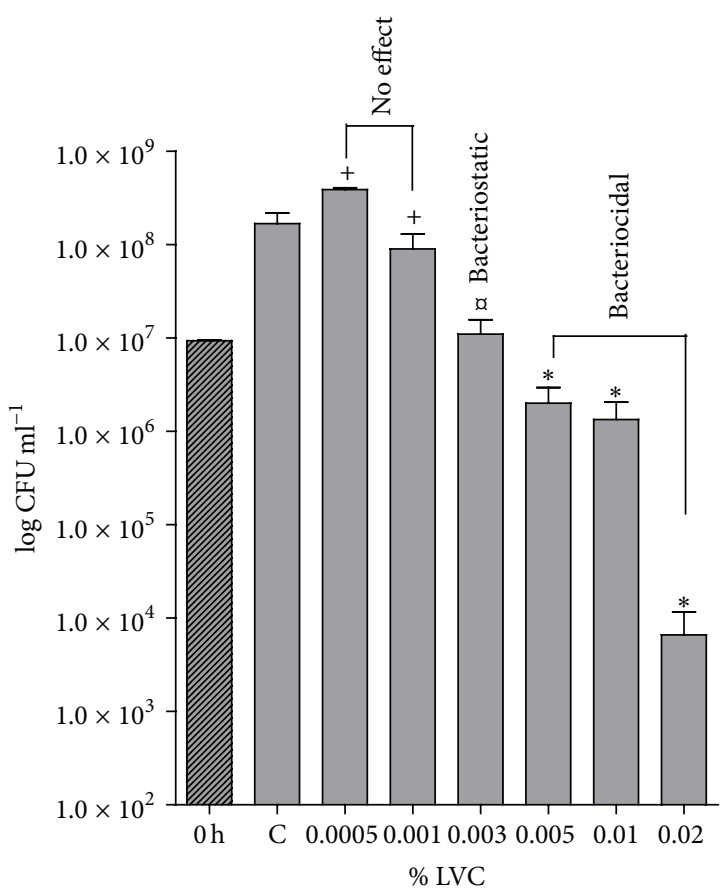

FIgURE 2: Planktonic growth $\left(\mathrm{CFU} \mathrm{mL}^{-1}\right)$ of $S$. epidermidis at 0 hours (before incubation) and after 18 hours of incubation in medium with LVC at concentrations ranging from 0.0005 to $0.02 \% \mathrm{w} / \mathrm{v}(n=12)$. Control $(\mathrm{C})$ : medium with $\mathrm{pH} 5.9$ without LVC. $*$ : reduced $\mathrm{CFU} \mathrm{mL} \mathrm{m}^{-1}$ compared to $\mathrm{C}$ and $0 \mathrm{~h}$; $\mathrm{a}$ : reduced $\mathrm{CFU} \mathrm{mL} \mathrm{m}^{-1}$ compared to $\mathrm{C}$ (but not to 0 hours); + : $\mathrm{CFU} \mathrm{mL} \mathrm{m}^{-1}$ corresponding to C.

level of $p<0.05$. The analyses were performed with GraphPad Prism version 4.00 for Windows.

\section{Results}

3.1. Planktonic Growth in Media with and without LVC. The bacteriostatic and bactericidal effects of LVC were evaluated using different concentrations of LVC (0 to $0.02 \% \mathrm{w} / \mathrm{v})$ in medium after 18-hour growth of S. epidermidis. Low concentrations of LVC, 0.0005 and $0.001 \% \mathrm{w} / \mathrm{v}$, did not induce effects on the growth of $S$. epidermidis. However, at higher concentrations of LVC, a bacteriostatic effect on the growth was observed $(0.003 \% \mathrm{w} / \mathrm{v})$, and at concentrations above $0.005 \% \mathrm{w} / \mathrm{v}$, LVC exhibited a bactericidal effect against $S$. epidermidis (Figure 2).

3.2. Growth of Biofilm in Media with and without LVC. LVC increased biofilm formation at concentrations below the observed bacteriostatic concentrations from the planktonic experiments. However, increasing LVC concentrations above $0.003 \% \mathrm{w} / \mathrm{v}$ significantly reduced biofilm formation in a concentration dependent manner (Figure 3).

3.3. Modified Direct Contact Test. The bactericidal effect of LVC-coated surfaces was evaluated using the modified direct contact test. LVC coatings exhibited a bactericidal effect against $S$. epidermidis, with a 2-3-log reduction compared to the control. Increasing the concentration of LVC from 


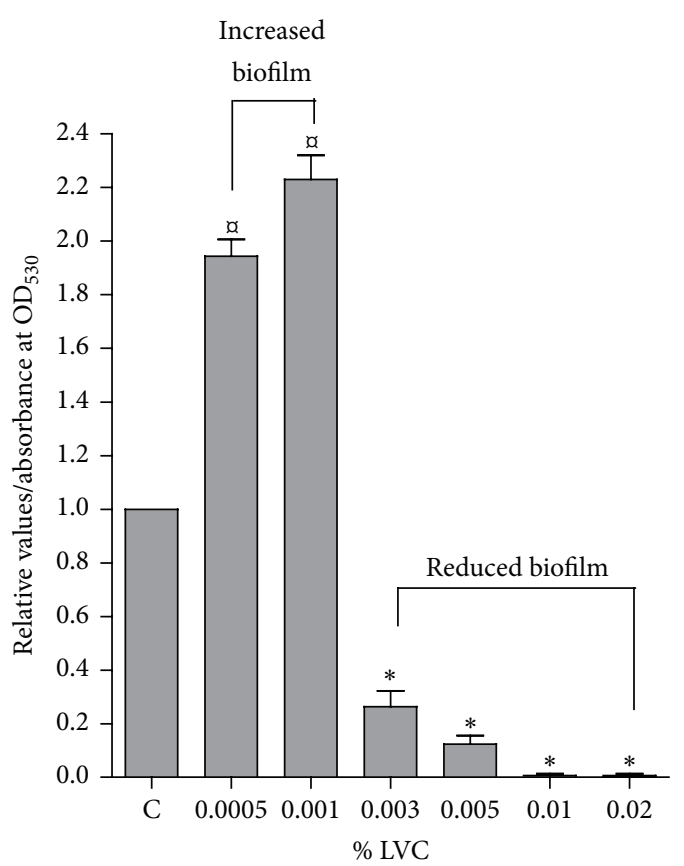

FIGURE 3: Formation of biofilm of $S$. epidermidis in medium with LVC at concentrations ranging from 0.0005 to $0.02 \% \mathrm{w} / \mathrm{v}(n=12)$. Amount of safranin-stained biomass after 18 hours is expressed as optical density $\left(\mathrm{OD}_{530}\right)$ relative to control (C). Control: medium with $\mathrm{pH} 5.9$ without LVC. $*: \mathrm{OD}_{530}$ significantly reduced compared to $\mathrm{C}$; $: \mathrm{OD}_{530}$ significantly increased compared to $\mathrm{C}$.

0.25 to $1 \% \mathrm{w} / \mathrm{v}$ when coating the surface did not increase the bactericidal effect of LVC against S. epidermidis (Figure 4).

3.4. Growth of Biofilm on Polystyrene Discs Coated with LVC. Biofilm formation on coated polystyrene discs using different concentrations of LVC in BHI was investigated after 6 and 18 hours. The amount of biofilm formed after 6 hours at the three concentrations of LVC investigated was significantly lower compared to control. There were no significant differences in the amount of biofilm between the three LVC coatings (Figure 5(a)). After 18 hours, there was significantly less biofilm formation on coatings made with 0.5 and $1 \% \mathrm{w} / \mathrm{v}$ LVC. However, the coating prepared with $0.25 \% \mathrm{w} / \mathrm{v} \mathrm{LVC} \mathrm{did}$ not reduce biofilm formation after 18 hours (Figure 5(b)). Scanning electron microscopy images of LVC-coated discs showed that LVC was distributed throughout the surface of the discs (Figure 6(b)). Images of biofilm on coated and uncoated discs verified that the LVC coating reduced the amount of biofilm compared to control (Figures 6(a) and 6(b)).

\section{Discussion}

As bacteria on indwelling devises and implants are developing resistance to common antibiotics, new approaches to prevent bacterial growth and biofilm formation are needed. Natural antimicrobial substances, such as chitosan, are therefore relevant alternatives for use as surface coatings to prevent

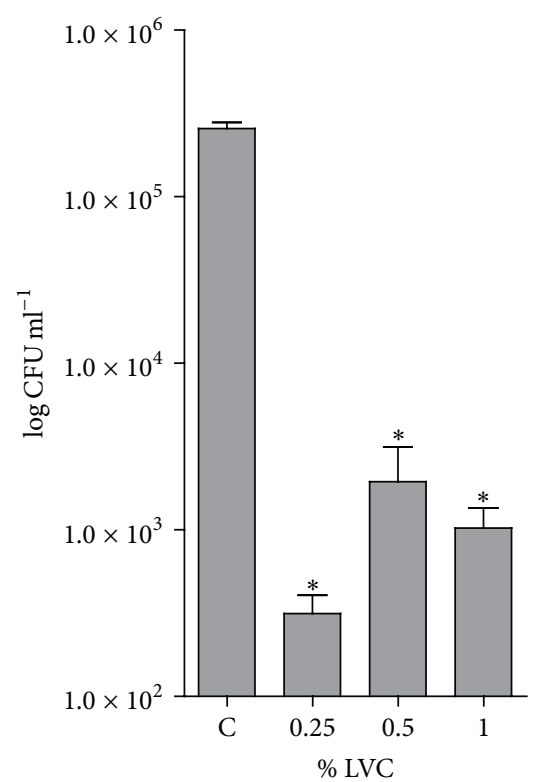

Figure 4: The bactericidal effect of LVC coatings $(0.25,0.5$, and $1 \% \mathrm{w} / \mathrm{v})$ as measured by the modified direct contact test $\left(\mathrm{CFU} \mathrm{mL} \mathrm{m}^{-1}\right)$ relative to control $(\mathrm{C})(n=8)$. Control: $0.5 \% \mathrm{HCl}$. $*$ : CFU mL $\mathrm{mL}^{-1}$ significantly reduced compared to $\mathrm{C}$.

and inhibit biofilm formation of bacteria. CNS, especially $S$. epidermidis, is one of the most notable and frequently found bacteria associated with infected implants [6].

The antimicrobial effect of chitosan has been linked to the positively charged amino groups $\left(\mathrm{NH}_{3}{ }^{+}\right)$of chitosan. These groups are suggested to participate in an electrostatic interaction with the negatively charged groups on the bacterial surface [25]. This interaction may cause damage to the cell wall and alter its permeability and barrier properties [26]. Chitosan's antibacterial and biofilm inhibitory efficiency vary for different species of bacteria [16, 27]. This may partly be explained by differences in the cell wall and expression of different surface molecules, in addition to differences in size, molecular weight, and deacetylation of chitosan itself [28]. In this study, the LVC used had a MW of $150 \mathrm{kDa}$ and chitosan of this size has shown good solubility $(9.98 \mathrm{mg} / \mathrm{mL})$ in phosphate buffer and good antibacterial effect at pH 6 [29]. The antibacterial activity of dissolved chitosan is dependent on the $\mathrm{pH}$ of the solution, and the antibacterial effect is reduced at higher $\mathrm{pH}$ due to less positive charged amino groups [30]. In our study, LVC precipitated out of the media when the $\mathrm{pH}$ was raised to 6 and higher. We therefore lowered the $\mathrm{pH}$ of the media to 5.9 with an organic acid and recorded good growth of $S$. epidermidis. LVC decreased planktonic growth in a concentration dependent manner when added to the growth medium and exhibited bactericidal effects at higher concentrations. In addition, LVC reduced biofilm formation of $S$. epidermidis, both when exposed to LVC directly in media and when coated on surfaces. The modified direct contact test also confirmed the bactericidal effect of LVC. These results are in accordance with studies on other Gram-positive organisms [20]. 


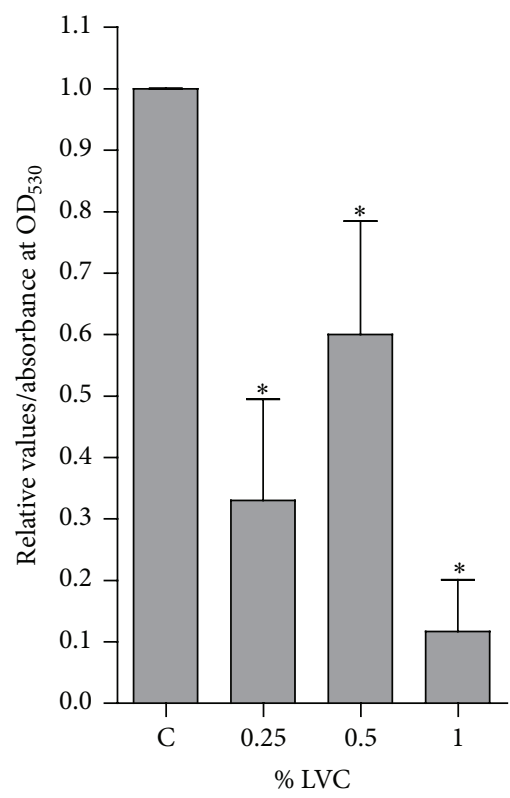

(a)

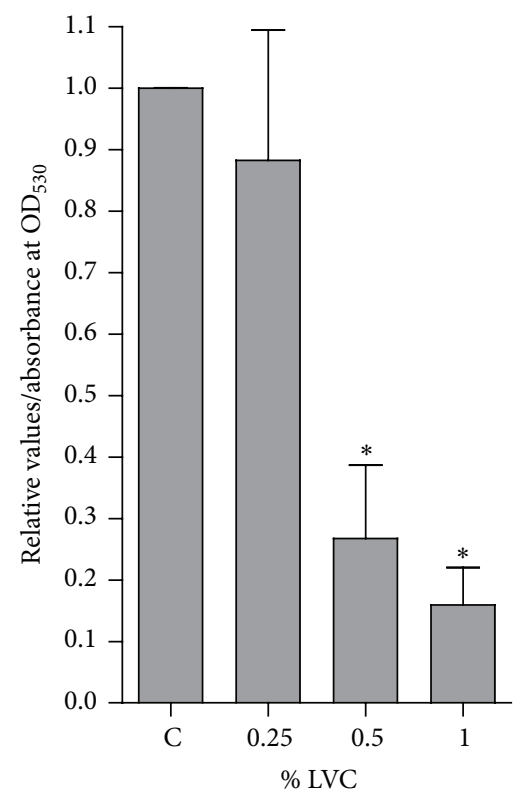

(b)

FIGURE 5: Biofilm of S. epidermidis stained with safranin after 6-hour (a) and 18-hour (b) incubation on polystyrene discs coated with LVC $(0.25,0.5$, and $1 \% \mathrm{w} / \mathrm{v})(n=12)$. Amount of biomass is expressed as optical density $\left(\mathrm{OD}_{530}\right)$ relative to control $(\mathrm{C})$. Control: discs coated with $0.5 \% \mathrm{HCl} . *: \mathrm{OD}_{530}$ significantly reduced compared to $\mathrm{C}$.
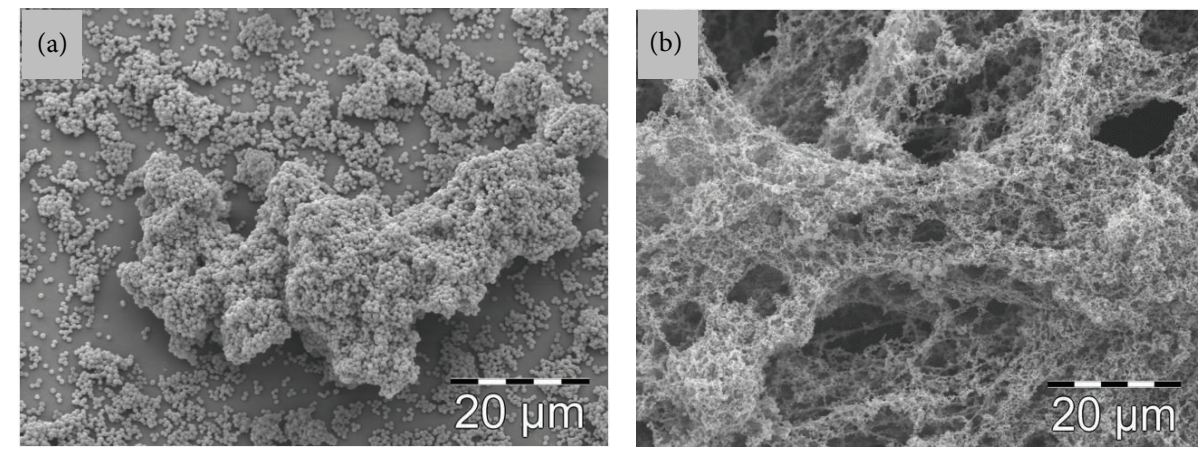

FIGURE 6: (a) SEM image of polystyrene disc with 6-hour biofilm of S. epidermidis. (b) SEM image of polystyrene disc coated with $0.25 \%$ w/v LVC with 6-hour biofilm of S. epidermidis.

Experiments with biofilm and LVC in media showed no antibiofilm effect at low concentrations. Instead, a considerable increase in the biofilm formation was observed. This suggests a stimulating function of LVC at low concentrations, as has been reported for other antimicrobial compounds when applied in low concentrations [31]. Different antibiotics and $\mathrm{NaCl}$ have also increased biofilm formation of $S$. epidermidis at potentially toxic concentrations, which was partly explained by the increased expression of polysaccharide intercellular adhesin (PIA), which constitutes the main component of the biofilm matrix [32]. The increased biofilm mass may indicate that these concentrations of LVC may activate a stress response in S. epidermidis, which has been shown to increase biofilm formation [33]. In addition, it has been reported that chitosan may lower the metabolic activity of S. epidermidis biofilm on intravenous catheters at subinhibitory concentrations [14].

The modified direct contact test used in this study has also been used to evaluate the bactericidal effect of sutures and nanoparticles $[34,35]$. We observed that the concentrations tested caused a considerable reduction of the number of CFU, $\sim 99 \%$, compared to control. However, increasing the concentration above $0.25 \% \mathrm{w} / \mathrm{v}$ did not further increase the bactericidal effect of LVC, which may indicate that the surface was saturated. Similarly, results from the coating experiments on polystyrene discs at 6-hour incubation did not depict a concentration dependent behavior for the LVC-coated surfaces at concentrations above $0.25 \% \mathrm{w} / \mathrm{v}$. Compared with LVC in media, where all bacteria and the whole cell are exposed to LVC, coatings of LVC only come into contact with 
bacteria in the media through the surface of the polystyrene discs. The SEM images showed that LVC coatings formed a dense network on the surface of the polystyrene discs.

Plexiglas coated with $1 \% \mathrm{w} / \mathrm{v}$ chitosan solution has shown superior antibiofilm effect on S. epidermidis compared with several common antiseptic and antibiotic coatings [19]. All three concentrations of LVC coatings on polystyrene discs reduced biofilm formation after 6-hour growth. However, after 18 hours, the lowest concentration of LVC investigated showed increased biofilm compared to early biofilm formation after 6 hours, showing a loss of biofilm inhibitory capacity during longer incubation periods. This phenomenon was however not evident for the higher concentrations of LVC investigated. These results demonstrate the importance of considering the concentrations and the incubation period when investigating the antibiofilm efficiency of chitosan and similar substances.

In this study, we report that LVC has a bacteriostatic and bactericidal activity against $S$. epidermidis and that the activity is dependent on the amount of LVC in media. In addition, LVC reduces biofilm formation both when added to media and when coated on polystyrene surfaces. We propose that LVC can be used as a natural antibacterial material as a coating or by incorporation into different biomaterials.

\section{Competing Interests}

The authors declared no conflict of interests.

\section{Acknowledgments}

The authors are grateful to S. Stølen at the Faculty of Dentistry, University of Oslo, Norway, for helping them perform the scanning electron microscopy.

\section{References}

[1] K. L. Rogers, P. D. Fey, and M. E. Rupp, "Coagulase-negative staphylococcal infections," Infectious Disease Clinics of North America, vol. 23, no. 1, pp. 73-98, 2009.

[2] M. E. Rupp, "Clinical characteristics of infections in humans due to Staphylococcus epidermidis," Methods in Molecular Biology, vol. 1106, pp. 1-16, 2014.

[3] M. T. McCann, B. F. Gilmore, and S. P. Gorman, "Staphylococcus epidermidis device-related infections: pathogenesis and clinical management," Journal of Pharmacy and Pharmacology, vol. 60, no. 12, pp. 1551-1571, 2008.

[4] J. L. Del Pozo and R. Patel, "The challenge of treating biofilmassociated bacterial infections," Clinical Pharmacology \& Therapeutics, vol. 82, no. 2, pp. 204-209, 2007.

[5] P. S. Stewart and J. W. Costerton, "Antibiotic resistance of bacteria in biofilms," The Lancet, vol. 358, no. 9276, pp. 135-138, 2001.

[6] I. Uçkay, D. Pittet, P. Vaudaux, H. Sax, D. Lew, and F. Waldvogel, "Foreign body infections due to Staphylococcus epidermidis," Annals of Medicine, vol. 41, no. 2, pp. 109-119, 2009.

[7] M. Widerström, T. Monsen, C. Karlsson, H. Edebro, A. Johansson, and J. Wiström, "Clonality among multidrug-resistant hospital-associated Staphylococcus epidermidis in northern
Europe," Scandinavian Journal of Infectious Diseases, vol. 41, no. 9, pp. 642-649, 2009.

[8] C. Claesson, A. Hällgren, M. Nilsson, E. Svensson, H. Hanberger, and L. Nilsson, "Susceptibility of staphylococci and enterococci to antimicrobial agents at different ward levels in four north European countries," Scandinavian Journal of Infectious Diseases, vol. 39, no. 11-12, pp. 1002-1012, 2007.

[9] C. Schaschke and J.-L. Audic, "Editorial, biodegradable materials," International Journal of Molecular Sciences, vol. 15, no. 11, pp. 21468-21475, 2014.

[10] D. Fu, B. Han, W. Dong, Z. Yang, Y. Lv, and W. Liu, "Effects of carboxymethyl chitosan on the blood system of rats," Biochemical and Biophysical Research Communications, vol. 408, no. 1, pp. 110-114, 2011.

[11] A. K. Singla and M. Chawla, "Chitosan: some pharmaceutical and biological aspects-an update," Journal of Pharmacy and Pharmacology, vol. 53, no. 8, pp. 1047-1067, 2001.

[12] M. Rinaudo, "Chitin and chitosan: properties and applications," Progress in Polymer Science, vol. 31, no. 7, pp. 603-632, 2006.

[13] B. K. Park and M.-M. Kim, "Applications of chitin and its derivatives in biological medicine," International Journal of Molecular Sciences, vol. 11, no. 12, pp. 5152-5164, 2010.

[14] L. Cobrado, M. M. Azevedo, A. Silva-Dias, J. P. Ramos, C. PinaVaz, and A. G. Rodrigues, "Cerium, chitosan and hamamelitannin as novel biofilm inhibitors?" Journal of Antimicrobial Chemotherapy, vol. 67, no. 5, pp. 1159-1162, 2012.

[15] K. Cooksey, "Effectiveness of antimicrobial food packaging materials," Food Additives and Contaminants, vol. 22, no. 10, pp. 980-987, 2005.

[16] M. Kong, X. G. Chen, K. Xing, and H. J. Park, “Antimicrobial properties of chitosan and mode of action: a state of the art review," International Journal of Food Microbiology, vol. 144, no. 1, pp. 51-63, 2010.

[17] I. Younes, S. Sellimi, M. Rinaudo, K. Jellouli, and M. Nasri, "Influence of acetylation degree and molecular weight of homogeneous chitosans on antibacterial and antifungal activities," International Journal of Food Microbiology, vol. 185, pp. 57-63, 2014.

[18] P. Renoud, B. Toury, S. Benayoun, G. Attik, and B. Grosgogeat, "Functionalization of titanium with chitosan via silanation: evaluation of biological and mechanical performances," PLoS ONE, vol. 7, no. 7, Article ID e39367, 2012.

[19] R. P. Carlson, R. Taffs, W. M. Davison, and P. S. Stewart, "Anti-biofilm properties of chitosan-coated surfaces," Journal of Biomaterials Science, Polymer Edition, vol. 19, no. 8, pp. 10351046, 2008.

[20] F. K. Tavaria, J. C. Soares, I. L. Reis, M. H. Paulo, F. X. Malcata, and M. E. Pintado, "Chitosan: antimicrobial action upon staphylococci after impregnation onto cotton fabric," Journal of Applied Microbiology, vol. 112, no. 5, pp. 1034-1041, 2012.

[21] V. E. Tikhonov, E. A. Stepnova, V. G. Babak et al., "Bactericidal and antifungal activities of a low molecular weight chitosan and its N-/2(3)-(dodec-2-enyl)succinoyl/-derivatives," Carbohydrate Polymers, vol. 64, no. 1, pp. 66-72, 2006.

[22] K. W. Kim, B. J. Min, Y.-T. Kim, R. M. Kimmel, K. Cooksey, and S. I. Park, "Antimicrobial activity against foodborne pathogens of chitosan biopolymer films of different molecular weights," LWT_Food Science and Technology, vol. 44, no. 2, pp. 565-569, 2011. 
[23] H. K. No, N. Park, S. Lee, and S. P. Meyers, "Antibacterial activity of chitosans and chitosan oligomers with different molecular weights," International Journal of Food Microbiology, vol. 74, no. 1-2, pp. 65-72, 2002.

[24] E. J. Jung, D. K. Youn, S. H. Lee, H. K. No, J. G. Ha, and W. Prinyawiwatkul, "Antibacterial activity of chitosans with different degrees of deacetylation and viscosities," International Journal of Food Science and Technology, vol. 45, no. 4, pp. 676682, 2010.

[25] H. Liu, Y. Du, X. Wang, and L. Sun, "Chitosan kills bacteria through cell membrane damage," International Journal of Food Microbiology, vol. 95, no. 2, pp. 147-155, 2004.

[26] Y.-C. Chung and C.-Y. Chen, "Antibacterial characteristics and activity of acid-soluble chitosan," Bioresource Technology, vol. 99, no. 8, pp. 2806-2814, 2008.

[27] B. Orgaz, M. M. Lobete, C. H. Puga, and C. S. Jose, "Effectiveness of chitosan against mature biofilms formed by food related bacteria," International Journal of Molecular Sciences, vol. 12, no. 1, pp. 817-828, 2011.

[28] H. Mellegård, S. P. Strand, B. E. Christensen, P. E. Granum, and S. P. Hardy, "Antibacterial activity of chemically defined chitosans: influence of molecular weight, degree of acetylation and test organism," International Journal of Food Microbiology, vol. 148, no. 1, pp. 48-54, 2011.

[29] S.-H. Chang, H.-T. V. Lin, G.-J. Wu, and G. J. Tsai, "pH effects on solubility, zeta potential, and correlation between antibacterial activity and molecular weight of chitosan," Carbohydrate Polymers, vol. 134, pp. 74-81, 2015.

[30] J. Champer, J. Patel, N. Fernando, E. Salehi, V. Wong, and J. Kim, "Chitosan against cutaneous pathogens," AMB Express, vol. 3, article 37, 2013.

[31] A. Houari and P. Di Martino, "Effect of chlorhexidine and benzalkonium chloride on bacterial biofilm formation," Letters in Applied Microbiology, vol. 45, no. 6, pp. 652-656, 2007.

[32] S. Rachid, K. Ohlsen, W. Witte, J. Hacker, and W. Ziebuhr, "Effect of subinhibitory antibiotic concentrations on polysaccharide intercellular adhesin expression in biofilmforming Staphylococcus epidermidis," Antimicrobial Agents and Chemotherapy, vol. 44, no. 12, pp. 3357-3363, 2000.

[33] B. Zhang, S. Halouska, C. E. Schiaffo, M. R. Sadykov, G. A. Somerville, and R. Powers, "NMR analysis of a stress response metabolic signaling network," Journal of Proteome Research, vol. 10, no. 8, pp. 3743-3754, 2011.

[34] S. Matalon, A. Kozlovsky, A. Kfir, S. Levartovsky, Y. Mazor, and H. Slutzky, "The effect of commonly used sutures on inflammation inducing pathogens-an in vitro study," Journal of Cranio-Maxillofacial Surgery, vol. 41, no. 7, pp. 593-597, 2013.

[35] N. Beyth, Y. Houri-Haddad, L. Baraness-Hadar, I. YudovinFarber, A. J. Domb, and E. I. Weiss, "Surface antimicrobial activity and biocompatibility of incorporated polyethylenimine nanoparticles," Biomaterials, vol. 29, no. 31, pp. 4157-4163, 2008. 

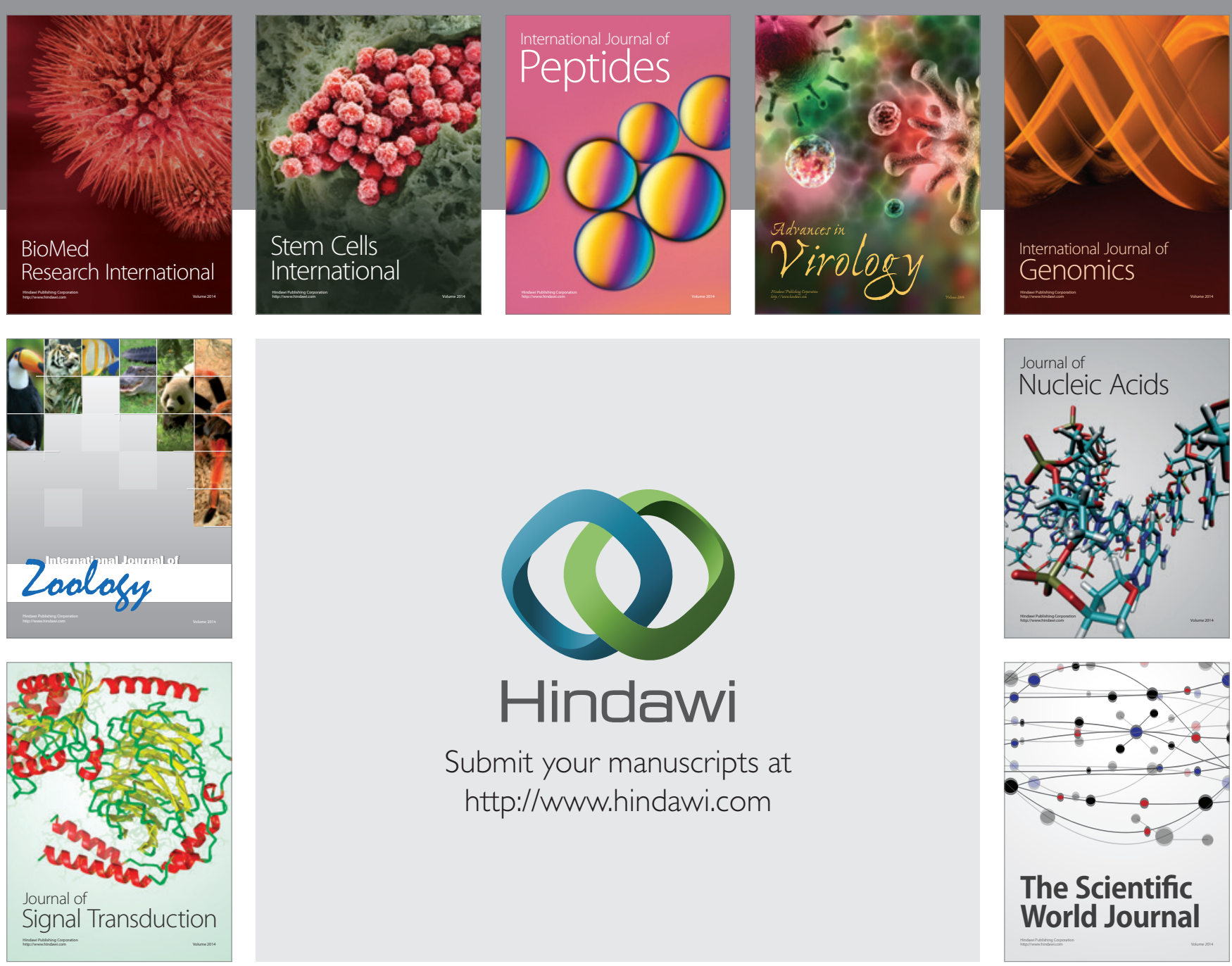

Submit your manuscripts at

http://www.hindawi.com
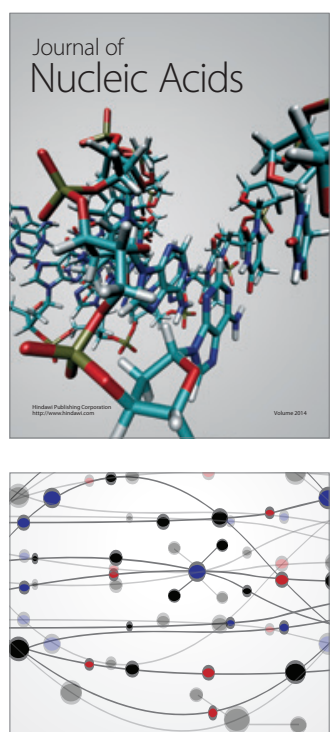

The Scientific World Journal
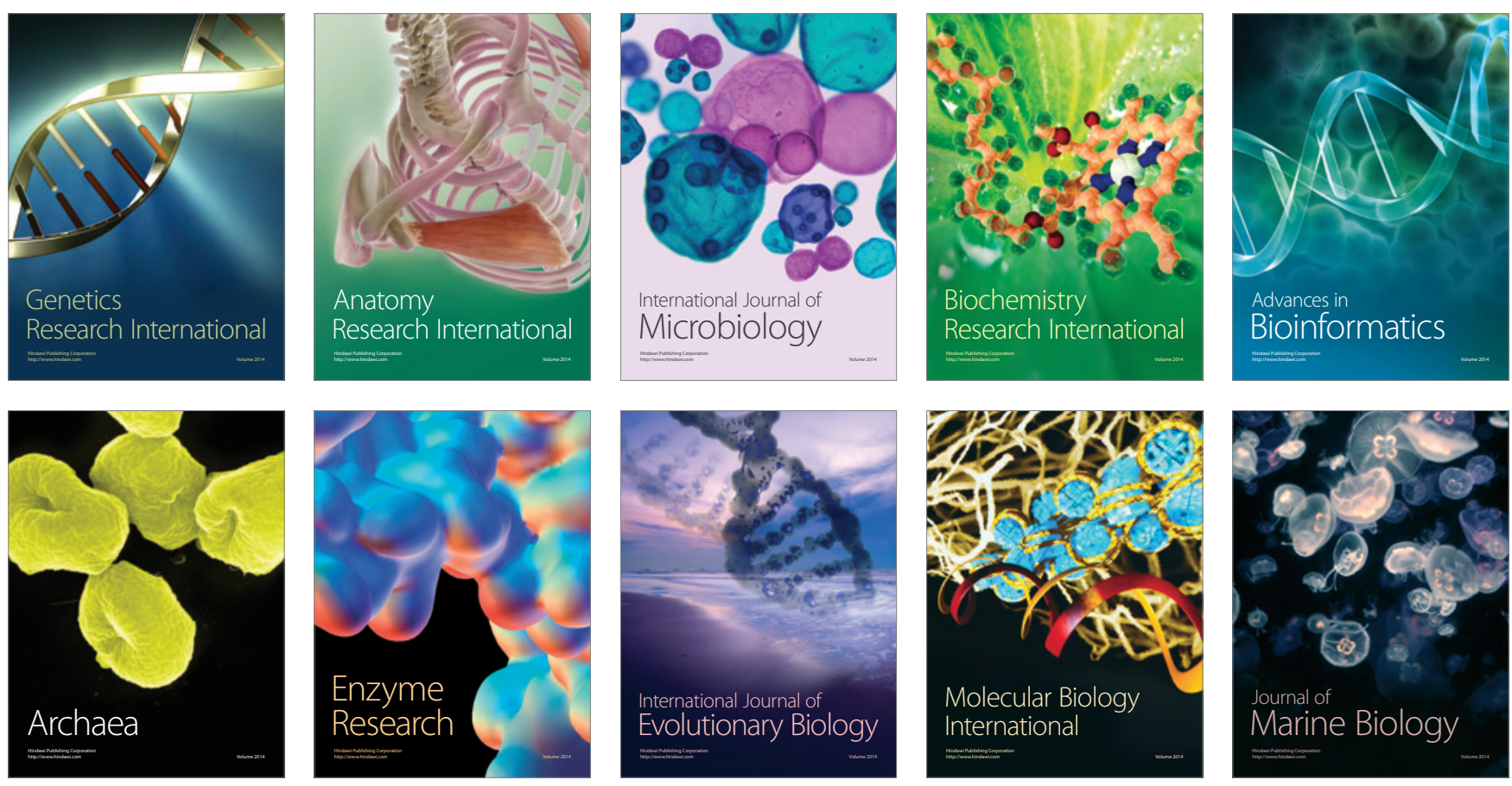